\title{
Laser cleaning of Cu-based artefacts: laser/corrosion products interaction
}

\author{
Elisabetta Di Francia ${ }^{1}$, Ruth Lahoz ${ }^{2}$, Delphine Neff ${ }^{3}$, Emma Angelini $^{1}$, Sabrina Grassini ${ }^{1}$ \\ ${ }^{1}$ Dipartimento di Scienza Applicata e Tecnologia, Politecnico di Torino, Torino, Italy \\ ${ }^{2}$ Centro de Química y Materiales de Aragón/CSIC - Universidad de Zaragoza, Zaragoza, Spain \\ ${ }^{3}$ LAPA NIMBE - IRAMAT, CEA/CNRS, Université Paris Saclay, Gif/YvetteParis-Saclay, France
}

\section{ABSTRACT}

This study aims to develop a low invasive and selective laser cleaning procedure for the removal of reactive corrosion products on Cubased artefacts without damage the substrate. In a preliminary step, laser cleaning was performed on two typologies of artificially corroded copper reference samples. The effect of the variation of laser parameters as pulse duration and output power, was thus evaluated on an oxide layer, simulating a protective patina, and a hydroxychloride layer, simulating a reactive corrosion products layer to be removed. The optimized cleaning procedure was validated on an archaeological artefact, a bronze coin. Morphological, microchemical and microstructural characterizations were performed by means of optical microscopy, confocal microscopy, field emission scanning electron microscopy, X-Ray diffraction and Raman spectroscopy, before and after laser cleaning. The experimental findings show that laser cleaning, in optimized conditions, can reduce the thickness of the hydroxychloride layers slightly affecting the oxide layers. The difference in the interaction with laser radiation of these two layers seems to be mainly related to the difference in grain size and porosity. Notwithstanding these encouraging results, in order to define the real feasibility of the laser cleaning procedure, a further validation on real artefacts is mandatory due to the variation in thickness and composition of the corrosion products formed during long-lasting uncontrolled degradation processes.

\section{Section: RESEARCH PAPER}

Keywords: Laser cleaning; fibre laser; archaeological bronze artefacts; artificial corrosion layer

Citation: Elisabetta Di Francia, Ruth Lahoz, Delphine Neff, Emma Angelini, Sabrina Grassini, Laser cleaning of Cu-based artefacts: laser-corrosion products interaction, Acta IMEKO, vol. 7, no. 3, article 16, October 2018, identifier: IMEKO-ACTA-07 (2018)-03-16

Section Editor: Egidio De Benedetto, University of Salento, Italy

Received May 18, 2018; In final form September 14, 2018; Published October 2018

Copyright: (C) 2018 IMEKO. This is an open-access article distributed under the terms of the Creative Commons Attribution 3.0 License, which permits unrestricted use, distribution, and reproduction in any medium, provided the original author and source are credited

Corresponding author: Elisabetta Di Francia, elisabetta.difrancia@polito.it

\section{INTRODUCTION}

The Cultural Heritage field is deeply related to metrological issues because measurements are involved in the characterisation and conservation of the artefacts and in the evaluation of the aggressiveness of the environment, which surrounds them [1-3]. Tangible Cultural Heritage is a fundamental witness of mankind history and has to be preserved for future generations, in all its multimateric assets, starting from proper cleaning procedures, to restoration and conservation in controlled environments.

Dealing with cleaning procedures, several studies may be found in literature on laser cleaning effects on artefacts, as natural stones, paintings, fossils and gilded metals [4-11]. Proper ablation conditions allow to assess the higher efficiency and selectivity of laser cleaning, with respect to traditional mechanical or chemical treatments. However, in the case of ancient metallic artefacts, a systematic investigation of the laser radiation/corrosion products interaction during cleaning is missing.

It has to be underlined the difficulty of this investigation due to the fact that the corrosion processes of archaeological $\mathrm{Cu}$ based artefacts, buried in soil for hundreds of years, lead to the formation of complex corrosion products layers with a stratified microstructure in dependence of the soil chemical-physical properties and of the environmental conditions [12-14]. As well known, corrosion of $\mathrm{Cu}$-based artefacts gives rise to at least two different layers: an inner one mainly constituted by cuprite, $\mathrm{Cu}_{2} \mathrm{O}$, grown directly in contact with the substrate, is the socalled noble patina, which can protect the metallic surface from further interaction with aggressive agents; an outer one, constituted by different chemical compounds in dependence of the interaction with soil constituents $(\mathrm{Cl}, \mathrm{P}, \mathrm{Si}, \mathrm{Fe}, \mathrm{Al}, \mathrm{K}, \mathrm{Ca}, \mathrm{S}$, 
$\mathrm{CO}_{2}$ ), oxygen and humidity. In the outer layers copper oxides and hydroxychlorides, sulphates and carbonates as malachite $\mathrm{Cu}_{2}(\mathrm{OH})_{2} \mathrm{CO}_{3}$, brochantite $\mathrm{Cu}_{4}(\mathrm{OH})_{6}(\mathrm{SO})_{4}$, atacamite and paracatamite $\mathrm{Cu}_{2}(\mathrm{OH})_{3} \mathrm{Cl}$, etc., may be found. Moreover, the presence of high concentration of chloride ions at the metal/corrosion layer interface leads to the formation of reactive cuprous chloride (nantokite, $\mathrm{CuCl}$ ), responsible of the cyclic copper corrosion processes well known as "bronze disease". Cuprous chloride exposed to humidity, cyclically reacts with oxygen and water, giving rise to the formation of the greenish $\mathrm{Cu}_{2}(\mathrm{OH})_{3} \mathrm{Cl}$ (atacamite and its polymorphs) that in turn reacts with copper to form new cuprous chloride and water. Copper, chlorine, oxygen and water are converted into cuprite, $\mathrm{Cu}_{2} \mathrm{O}$, and atacamite, $\mathrm{Cu}_{2}(\mathrm{OH})_{3} \mathrm{Cl}$, in a cyclical and continuous process that can damage the archaeological artefact. Non-invasive cleaning treatments able to remove the reactive corrosion products, preserving the protective patina could help in stopping this dangerous process.

In the ideal scenario of the laser ablation process, the laser radiation has to be absorbed by the corrosion products to be removed thanks to physical processes (plasma), while it has to be reflected by the metal. During the laser cleaning of ancient $\mathrm{Cu}-$ based artefacts, the laser parameters have to be optimised, in order to remove the reactive corrosion products and leave a thin layer of the protective patina onto the metallic substrate, as shown in the scheme of Figure 1.

However, to modelize the laser physical effect is extremely complex: different stratifications lead to different thermal effects, and consequently to different melting and evaporation behaviours which have to be understood and controlled in order to avoid any damage to the artefact, satisfying the conservation requirements highlighted by conservators and restorers.

Consequently, due to the high unpredictable inhomogeneity of the corrosion product layers on ancient $\mathrm{Cu}$-based artefacts, artificially corroded copper specimens were used, in this preliminary study, to assess the laser effects as a function of the corrosion products chemical composition [15-17] and to optimize the cleaning procedure [18].

As a matter of facts, the laser cleaning was performed on two typologies of artificially corroded copper reference samples. The effect of the variation of laser parameters as pulse duration and output power, was thus evaluated on an oxide layer, simulating a protective patina, and a hydroxychloride layer, simulating a reactive corrosion products layer to be removed. The optimized cleaning procedure was validated on an archaeological artefact, a bronze coin.

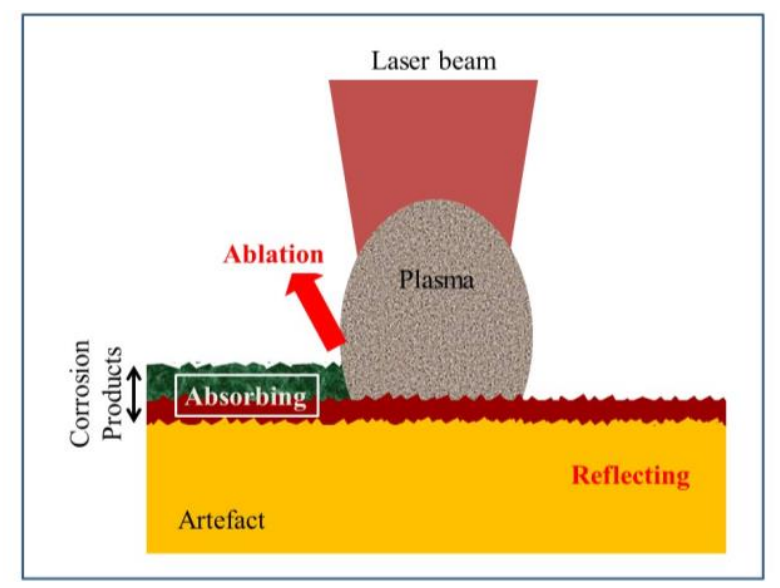

Figure 1. Metal and corrosion products behaviour under laser ablation: the laser ablates the reactive corrosion products (green) while the protective noble patina (brown) is preserved.

\section{MATERIALS AND METHODS}

Laser cleaning treatments were performed by means of a Near-IR (NIR) Yb:YAG fibre laser on a set of $\mathrm{Cu}$ reference samples artificially corroded, as described below.

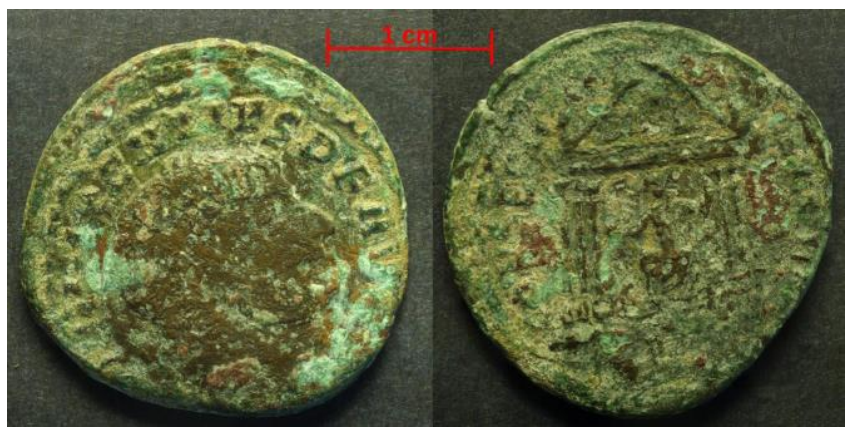

Figure 2. The Follis Massenzio coin: recto (left), verso (right). The images were taken with a high-resolution digital camera.

Laser cleaning treatment, in optimized conditions, was carried out on a Roman Empire bronze coin, shown in Figure 2, the Follis Massenzio coin coming from a private collection.

\subsection{Artificially corroded Cu reference samples}

A set of $\mathrm{Cu}$ reference samples $(45 \times 15 \times 5 \mathrm{~mm}$; Cu $99.96 \mathrm{wt} \%)$ were polished with 500 to 4000 -grid $\mathrm{SiC}$ paper, rinsed in ethanol in ultrasonic bath for $5 \mathrm{~min}$, and well dried.

Table 1. Scanning tests performed on the artificially corroded Cu reference samples.

\begin{tabular}{|c|c|c|c|c|c|}
\hline \multirow[b]{2}{*}{ Test } & \multicolumn{3}{|c|}{ Laser Parameters } & \multicolumn{2}{|c|}{ Geometrical parameters } \\
\hline & $\begin{array}{l}\text { Power, } \\
P \text { in W }\end{array}$ & $\begin{array}{c}\text { Fluence, } \\
F \text { in } \mathrm{J} / \mathrm{cm}^{2}\end{array}$ & $\begin{array}{c}\text { Pulse duration, } \\
t_{\mathrm{p}} \text { in } \mathrm{ns}\end{array}$ & $\begin{array}{l}\text { Scan speed, } \\
v_{\text {scan }} \text { in } \mathrm{mm} / \mathrm{s}\end{array}$ & $\begin{array}{c}\text { Interlining, } \\
d_{\mathrm{L}} \text { in } \mathrm{mm}\end{array}$ \\
\hline 1 & 0.23 & 1.63 & 4 & 300 & 0.015 \\
\hline 2 & 0.28 & 1.98 & 4 & 300 & 0.015 \\
\hline 3 & 0.42 & 2.97 & 4 & 300 & 0.015 \\
\hline 4 & 0.52 & 3.68 & 4 & 300 & 0.015 \\
\hline 5 & 0.73 & 5.16 & 4 & 300 & 0.015 \\
\hline 6 & 0.21 & 1.49 & 8 & 300 & 0.015 \\
\hline 7 & 0.25 & 1.77 & 8 & 300 & 0.015 \\
\hline 8 & 0.43 & 3.04 & 8 & 300 & 0.015 \\
\hline 9 & 0.58 & 4.10 & 8 & 300 & 0.015 \\
\hline 10 & 0.77 & 5.45 & 8 & 300 & 0.015 \\
\hline
\end{tabular}


Then, two different kinds of artificial corrosion layers were formed in order to mimic the presence of an oxide layer (simulating a protective patina) and a hydroxychloride layer (simulating a reactive corrosion products layer to be removed).

The oxide layer was obtained electrochemically: an anodic treatment was performed in $0.1 \mathrm{M} \mathrm{Na}_{2} \mathrm{SO}_{4}$ solution at room temperature [19] by applying a potential of $+0.084 \mathrm{~V}$ (vs $\mathrm{Ag} / \mathrm{AgCl}$ ) for $16 \mathrm{~h}$ to the $\mathrm{Cu}$ reference samples.

The hydroxychloride layer was obtained by two months immersion at room temperature of the $\mathrm{Cu}$ reference samples in $0.5 \mathrm{M} \mathrm{NaCl}$ solution, neither stirred or aerated.

\subsection{Laser cleaning treatments}

Optical fibre spectroscopy measurements, discussed in detail elsewhere [20], were performed to determine the spectral signature of corroded $\mathrm{Cu}$ samples as a function of the laser wavelength. The reflectance measurements exhibited a signature of the corrosion products from $\sim 600$ to $900 \mathrm{~nm}$. The highest gap in reflectance between the metallic substrate and the corrosion products layer is around $900 \mathrm{~nm}$, thus allowing the optimisation of the cleaning treatment.

A pumped diode Q-switched Yb:YAG fibre laser (model EasyMark-20 from Jeanologia), operating in the Near-IR at a wavelength of $1064 \mathrm{~nm}$ was used to perform the laser cleaning treatments. Pulses, with durations in the range $4-200$ ns, were delivered by means of two-galvanic mirrors and focused with a $\mathrm{f}$-Theta lens with $160 \mathrm{~mm}$ of focal distance. The laser system is coupled via computer with EzCAD 2.1 UNI, a vector graphic editor, with a CAD-like capability that enables users to perform rapid, precise and complex surface scanning treatments in a repeatable way. Moreover, the vector graphic editor allows to control the laser parameters (e.g. output power, $P$, and pulse duration, $\left.t_{\mathrm{p}}\right)$ and the geometrical ones.

Thermal interactions (e.g. melting) instead of ablation of the surface layer can be avoided adjusting pulse overlap, preventing thermal incubation and over irradiation. The overlap in X-axis is determined by the spot size and the scanning speed $v_{\text {scan, }}$ while overlap in Y-axis is defined by the spot size and the interlining $d_{\mathrm{L}}$.

Several laser cleaning tests, summarized in Table 1, were performed by varying pulse duration and power, directly related to the fluence, the pulsed power per area. The geometric parameters $\left(v_{\text {scan }}, d_{\mathrm{L}}\right)$ were chosen to guarantee the scanning of all the surface; a spot diameter of $30 \mu \mathrm{m}$ and an interlining of $15 \mu \mathrm{m}$ were used to insure a sufficient overlap and to cover all the irradiated areas.

\subsection{Samples characterisations}

Morphological, chemical and microstructural characterisations of the samples before and after laser cleaning, were performed both on the surface and on the cross-section. Cross-sections were prepared by embedding the samples in SpeciFix-20-Struers resin and polishing them with 500 to 4000 $\mathrm{SiC}$ paper and with $6 \mu \mathrm{m}$ to $1 \mu \mathrm{m}$ cloths.

High resolution digital photographs were taken by a digital camera $(4000 \times 3000$ pixels, Panasonic Lumix G2) equipped by a stand with a $3000 \mathrm{~K}$ lamp and by optical microscopy (Olympus BX51 microscope equipped with a Nikon EOS camera) in bright and in dark modality. Confocal microscopy profilers were acquired using a Sensofar PL $\mu 2300$ microscope using a 20x objective. Field emission scanning electron microscopy (FESEM, Zeiss, Supra40) images were collected in secondary electron and in field emission modes varying the acceleration voltage from $1.5 \mathrm{kV}$ to $15 \mathrm{kV}$. $\mu$ XRD diffraction patterns were obtained by a Rigaku RINT/RAPID instrument equipped with a $\mathrm{Cu}$ target; diffractions were acquired with the X-Ray source at $40 \mathrm{kV}$ and $20 \mathrm{~mA}$ with a $100 \mu \mathrm{m}$ collimator, in the range $10^{\circ}-160^{\circ} 2 \theta$. The qualitative analyses were performed by Rapid XRD software and the qualitative identification of the reflections were done by comparison with the PANalytical X'Pert HighScore Plus v3.0 software.

$\mu$ Raman analyses were performed under a Leica $x 50 / 0.85$ microscope objective and the spectra were acquired with a Renishaw Invia equipped with a doubled Nd:YAG laser $(532 \mathrm{~nm})$. The laser power on the sample surface was fixed to about $500 \mu \mathrm{W}$ in order to avoid the thermal transformation of the analysed phases. The experimental findings were compared with the spectra collected in a database composed from commercial or synthetic powders obtained in laboratory and by comparison to references of the literature [21].

Diffuse reflectance measurements were performed by means of CARY 5000 V1.12 (Varian®) in the wavelength range 220$1500 \mathrm{~nm}$, to determine the absorption performance of the corrosion products layers.

\section{RESULTS AND DISCUSSION}

\subsection{Laser cleaning of artificially corroded Cu reference samples}

The analysis of all the laser cleaned reference samples reveals that the best results in terms of higher ablation rates with the minimum thermal interaction effect on both the oxide and the hydroxychloride layers, were obtained utilizing the experimental parameters of test 1 , shown in Table 1 . They are characterised by: the shortest pulse duration $t_{p}, 4$ ns, utilized also in tests 2,3 , 4 , and 5 , while tests $6,7,8,9$, and 10 had a pulse duration $t_{p}$ of $8 \mathrm{~ns}$; the lowest power $P$ of $0.23 \mathrm{~W}$ and the lowest fluence $F$ of $1.63 \mathrm{~J} / \mathrm{cm}^{2}$ among the first five tests.

The results of the laser cleaning performed with the experimental parameters of Test 1, obtained due to the highest irradiation values, were chosen as the ablation threshold values and are discussed in detail.

Figure 3 shows the confocal microscope images of the oxide and hydroxychloride corrosion layers at the interface between laser treated and non-treated areas. Both the oxide and the hydroxychloride layers have a thickness in the range 35-40 $\mu \mathrm{m}$.

The average roughness and the standard deviation were calculated on 100,000 points on the confocal pictures. For the oxide layer, Figure $3 \mathrm{a}$, the surface of the non-treated area is characterised by a rough structure with a standard deviation of $1.96 \mu \mathrm{m}$; the laser cleaning removes about $1.6 \mu \mathrm{m}$ of this oxide layer and reduces the surface roughness to about $1.5 \mu \mathrm{m}$. In the case of the hydroxychloride layer, Figure $3 \mathrm{~b}$, the laser cleaning removes about $24 \mu \mathrm{m}$ and reduces the roughness from $11.9 \mu \mathrm{m}$ to $8.1 \mu \mathrm{m}$.
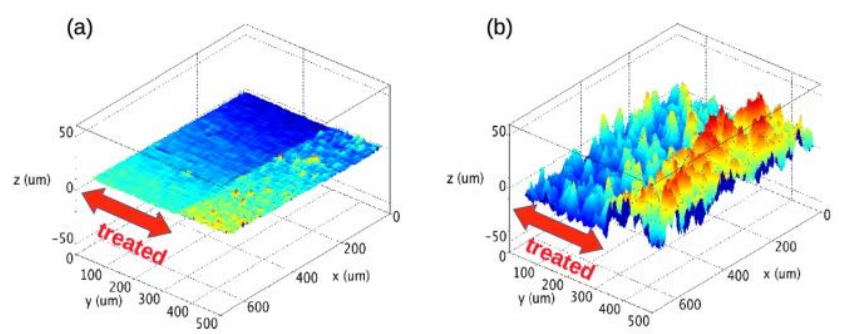

Figure 3. Confocal microscope images of the oxide (a) and hydroxychloride (b) corrosion layers grown on copper reference samples, at the interface between laser treated and non-treated area. 
Figure 4 shows the high-resolution and FESEM images of the oxide and hydroxychloride corrosion layers. From the highresolution images, a negligible colour change is observed, both for the oxide layer, (Figures 4a, 4c), and for the hydroxychloride layer (Figures $4 \mathrm{e}, 4 \mathrm{~g}$ ). On the contrary, the surface of the oxide layer before and after laser cleaning is characterised by a different macroscopic appearance, with a superficial melting of the oxide, that is evidenced by the FESEM image of Figure $4 \mathrm{~d}$, that if compared with the one of Figure $4 \mathrm{~b}$ highlights the modification of the laser treated surface. On the artificial hydroxychloride layer, the high-resolution images reveal a similar macroscopic appearance. On the FESEM images of Figures 4f, 4h, negligible changes in the corrosion layer morphology due to the laser treatment may be observed: the presence of crystals and their size, $5-10 \mu \mathrm{m}$, seem unaffected by the interaction with the laser radiation.

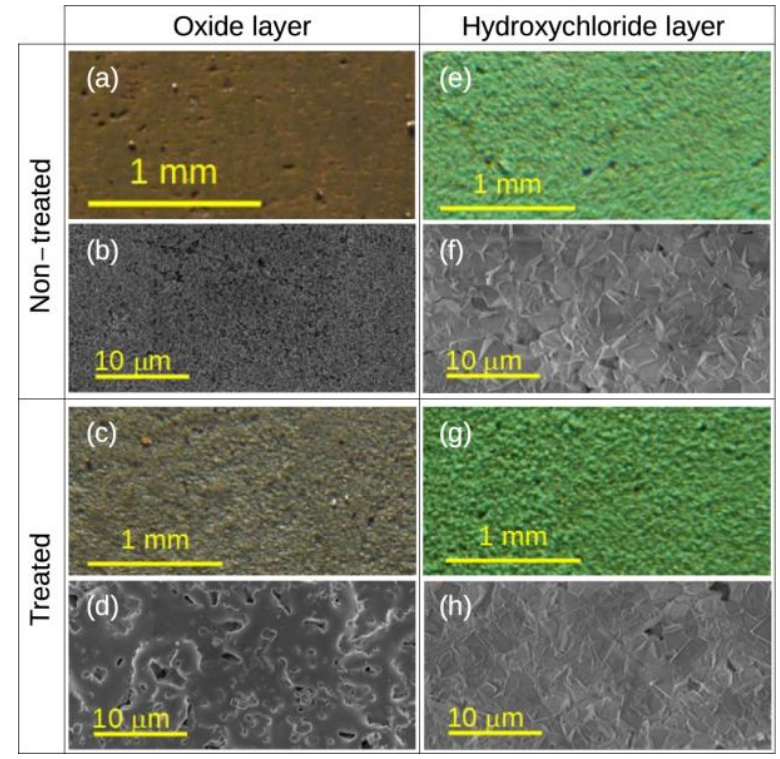

Figure 4. Images of the artificial oxide and hydroxychloride layers grown on the $\mathrm{Cu}$ reference samples, laser treated in the conditions of Test 1 and nontreated; images collected by high resolution camera $(a, c, e, g)$ and by FESEM (b, d, f, h).

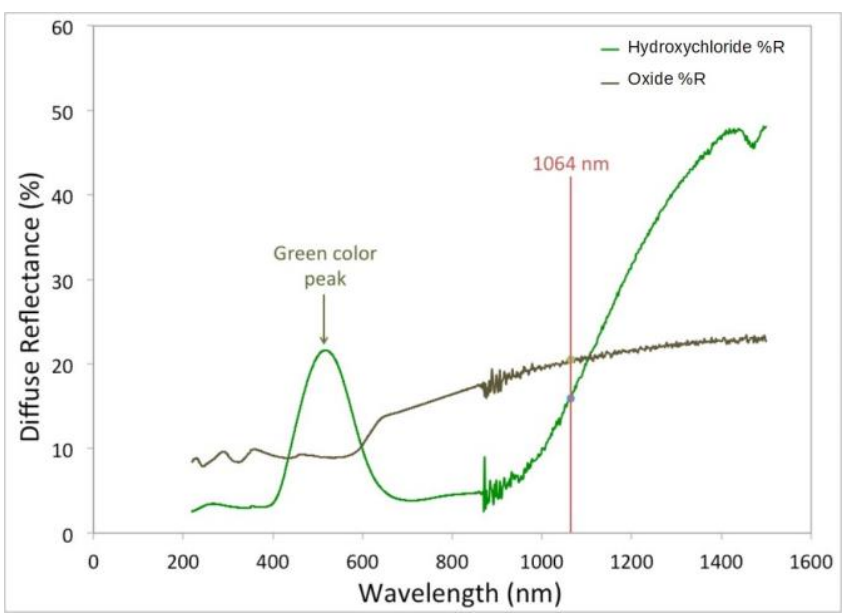

Figure 5. Diffuse reflectance of the oxide (brown) and hydroxychloride (green) corrosion layers.

The diffuse reflectance spectra of the two layers shown in Figure 5, reveal that, at a wavelength of $1064 \mathrm{~nm}$, the reflectance for the hydroxychloride layer is lower than the one of the oxide layer. This means that the ablation threshold is higher for cuprite, so this layer needs a higher energy to be removed. Consequently, during laser cleaning reasonably the oxide layer is better preserved, while the undesired hydroxychloride layer is partially ablated.

The different behaviour of the oxide and hydroxychloride layers may also be related to the different grain size and porosity of the corrosion products, as well as to the absorption mechanisms of the laser irradiance of each corrosion layer. As shown in the FESEM images, the untreated oxide layer, is characterized by lower grain size and higher porosity; while the hydroxychloride layer shows higher grain size and less porosity. The laser light absorption entity is noteworthy influenced by grain size dimensions. With smaller grain sizes, light scatters on multiple surfaces (grain borders) and there is less penetration into the surface, originating lower reflectance values [22]. For the porosity, the behaviour is similar, the higher the porosity the higher the scattering phenomena. This may explain the surface morphology observed after laser treatment, shown in Figure 4.
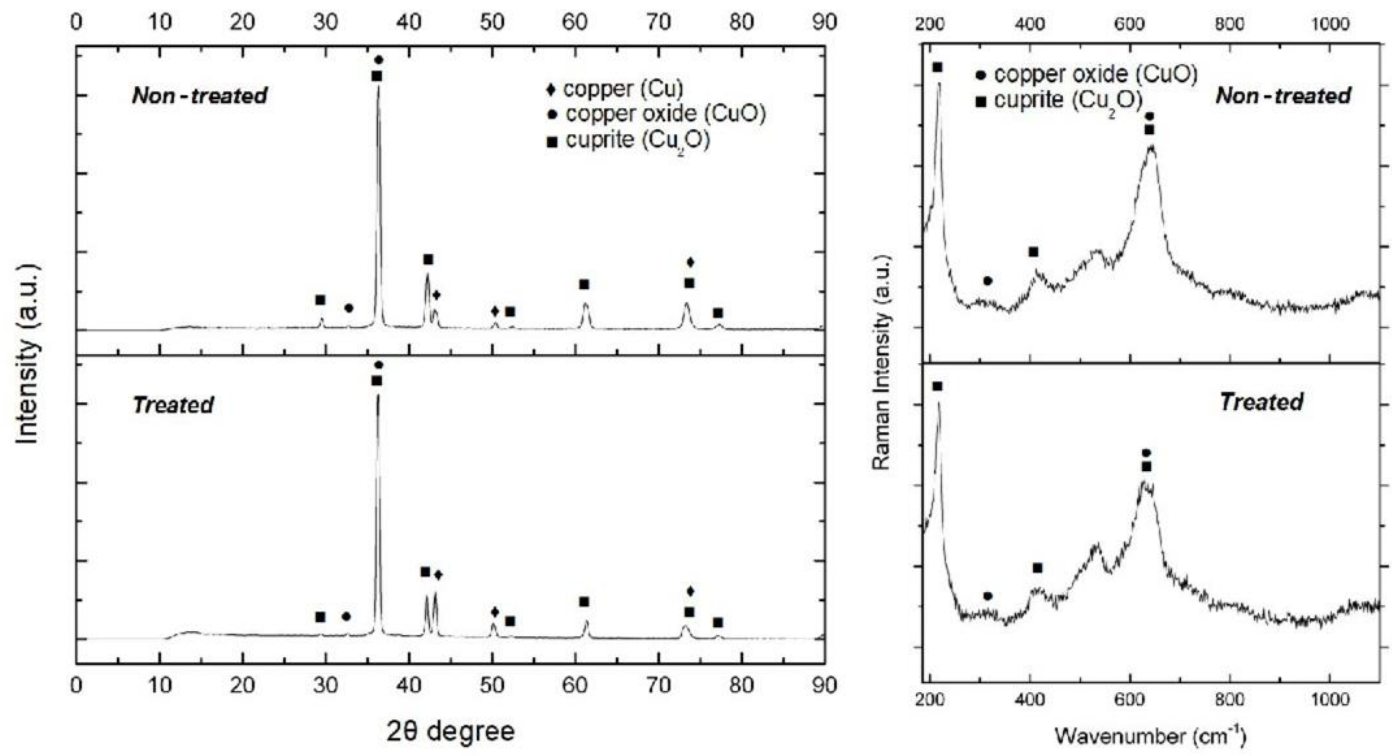

Figure 6. $\mu$ XRD and $\mu$ Raman spectra collected on the treated (Test- 1 ) and non-treated surfaces and cross-sections of the artificial oxide corrosion layer grown on $\mathrm{Cu}$ reference samples. ( $\mu$ XRD database: reference pattern-00-005-0667 cuprite, reference pattern-00-004-0836 copper, reference pattern-03-065-2309 copper oxide; $\mu$ Raman database: RUFF ID-120076 copper oxide; RUFF ID-050374-3 cuprite). 

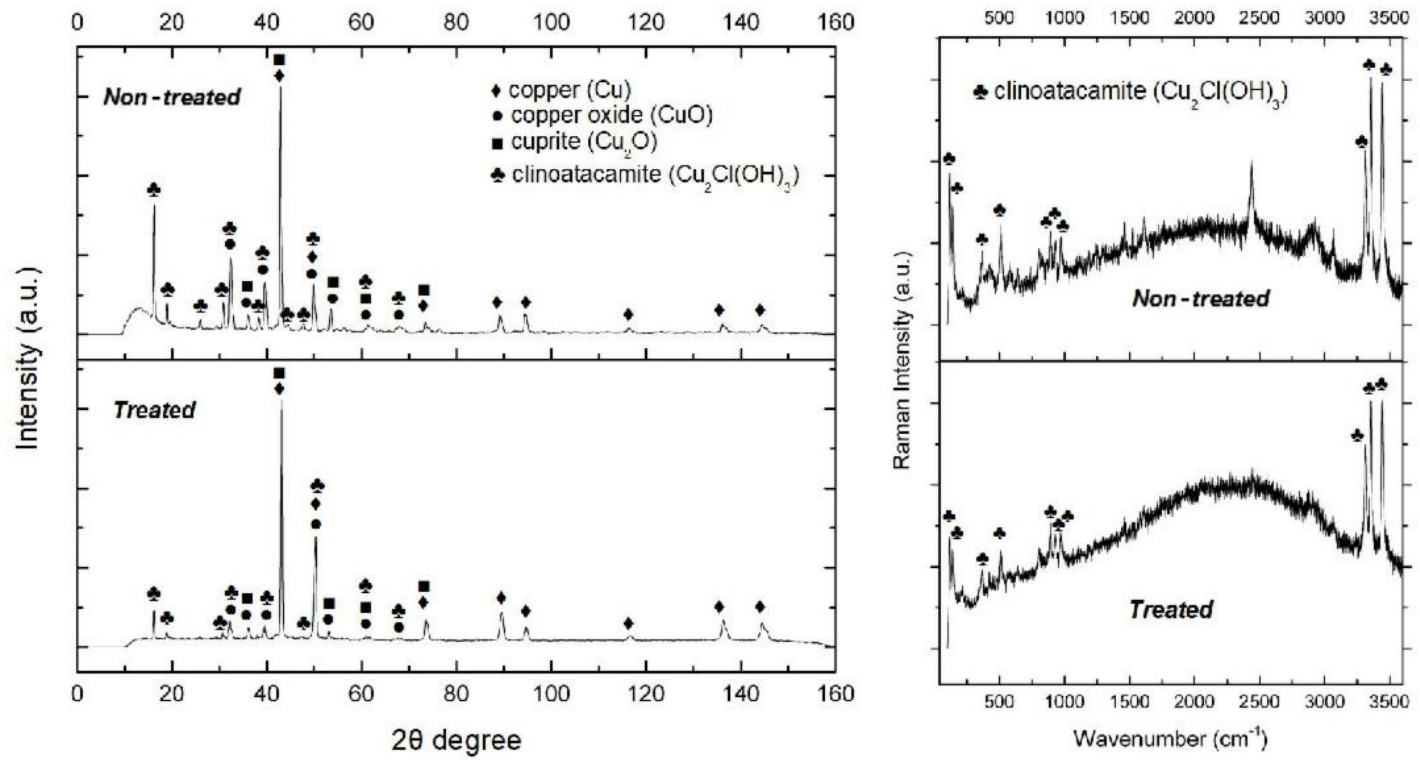

Figure 7. $\mu$ XRD and $\mu$ Raman spectra collected on the treated (Test- 1 ) and non-treated surfaces and cross-sections of the artificial hydroxychloride corrosion layer grown on Cu reference samples. ( $\mu$ XRD database: reference pattern-00-005-0667 cuprite, reference pattern-00-004-0836 copper, reference pattern-03065-2309 copper oxide, reference pattern-01-086-1391 clinoatacamite; $\mu$ Raman: [21] clinoatacamite).

The surface of the oxide layer laser irradiated appears melted. Laser absorption through the grain borders has started melting on those points. Hydroxychloride layer, with high absorption, remains with the same morphology since its big crystals microstructure reduces significantly the scattering effects, especially on the surface.

Supporting this discussion, previous work on laser cleaning of hydroxychloride layers characterized by grain sizes of high dimension have shown that the previously reported laser irradiation values do not affect big crystals shape [23].

$\mu \mathrm{XRD}$ analyses have been performed on the surfaces of the oxide and hydroxychloride corrosion layers, while $\mu$ Raman acquisitions have been performed on the cross-sections of the non-treated and treated areas.

The microchemical and microstructural characterisations show that the oxide layer created by the electrochemical treatment is mainly composed of cuprite $\left(\mathrm{Cu}_{2} \mathrm{O}\right)$, with the presence of tenorite $(\mathrm{CuO})$ grown directly in contact with the metal as highlighted by the diffraction patterns and Raman peaks of both phases, Figure 6. By comparing the $\mu$ XRD patterns collected on the treated and non-treated areas, a slight difference in the microstructure is detectable: the spectra show an increase of the relative intensity of the diffraction patterns associated to metallic copper onto the laser treated surface (Figure 5) probably associated to a reduction of the oxide layer thickness. Instead, from $\mu$ XRD analyses (Figure 7), the surface of the hydroxychloride layer, created by immersion in the chloride solution, is mainly composed of copper chlorides, such as clinoatacamite $\left(\mathrm{Cu}_{2} \mathrm{Cl}(\mathrm{OH})_{3}\right)$, and copper oxides $\left(\mathrm{CuO}, \mathrm{Cu}_{2} \mathrm{O}\right)$. Also, on this case onto the laser treated surface a slight increase of the metallic copper associated to a reduction in the relative intensities of the chloride components has been detected. $\mu$ Raman analyses confirm the presence of clinoatacamite $\left(\mathrm{Cu}_{2} \mathrm{Cl}(\mathrm{OH})_{3}\right)$ on both treated and non-treated areas (Figure 7) [21].

The analyses carried out on the artificially corroded reference samples have highlighted that the selected laser parameters are able to reduce the thickness of the hydroxychloride layer, slightly affecting the oxide layer. The difference on the corrosion layerlaser interactions seems to be mainly related to the difference in grain size and porosity of the oxide and hydrochloride layers. All these results highlight also that no changes in the composition of the corrosion layers seem to be induced by the laser cleaning treatment.

\subsection{Laser cleaning on an archaeological artefact}

The laser cleaning was performed on a fragment of the bronze coin of Figure 2. The bronze coin $(81.95 \mathrm{wt} \% \mathrm{Cu}, 4.1 \mathrm{wt} \% \mathrm{Sn}$, $\left.11 \mathrm{wt}^{\%} \% \mathrm{~Pb}, 2.95 \mathrm{wt} \% \mathrm{Ag}\right)$, had a more uniform greenish corrosion layer on the verso side (observe) than on the recto side (reverse), therefore the observe side was submitted to laser cleaning.

Figure 8 shows the high-resolution images of the coin fragment surface before and after the laser cleaning with the experimental parameters of Test 1 . In this case too only a negligible change in colour may be macroscopically observed.

The OM image of Figure 9 shows on the non-treated crosssection of the coin fragment, the presence of an external compact corrosion products layer, up to $200 \mu \mathrm{m}$ thick, and a less compact inner layer interconnected with the bulk metal up to $800 \mu \mathrm{m}$ thick is observed. Since the coin is a real artefact, the corrosion products layer is not uniform, both in composition and thickness, however, the results here presented refer to the more representative areas.

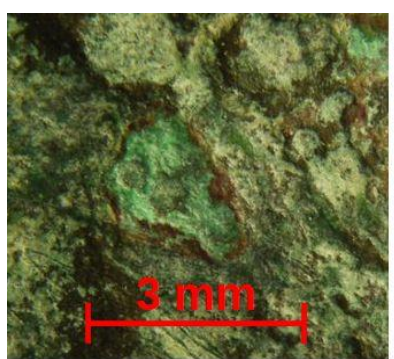

(a)

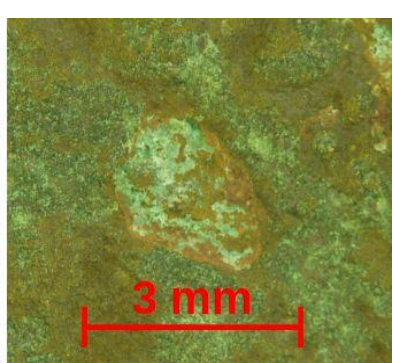

(b)
Figure 8. High-resolution images of the coin fragment surface before (a) and after (b) the laser cleaning (Test 1). 
Due to these differences, several measurements were performed on the treated and non-treated areas in order to evaluate the effect of laser in removing the corrosion products.

Figure 10 shows the dark-field optical microscope images of non-treated and treated cross-section areas of the coin. On the laser treated areas, the surface structure of the coin described above is still present. Moreover, it is possible to observe a reduction of the external corrosion product average thickness up to $30 \mu \mathrm{m}$, while the inner and less compact corrosion products layer has not been affected by the laser radiation.

Dealing with the chemical composition, the dark-field optical microscopy allows to associate different colours to different compositions: the red colour can be associated to the presence of $\mathrm{Cu}^{+}$compounds, while the green colour can be associated to the presence of $\mathrm{Cu}^{++}$compounds. The compact layer presents mainly $\mathrm{Cu}^{+}$compounds (e.g. copper oxide) in the part closer to the metal, while the upper part is characterised by the presence of $\mathrm{Cu}^{++}$compounds (e.g. hydroxycholoride polymorphs). From the microscopical and microstructural point of view, it seems that the laser treatment removed the copper chlorides in a quite controlled way, without damaging the metallic surface.

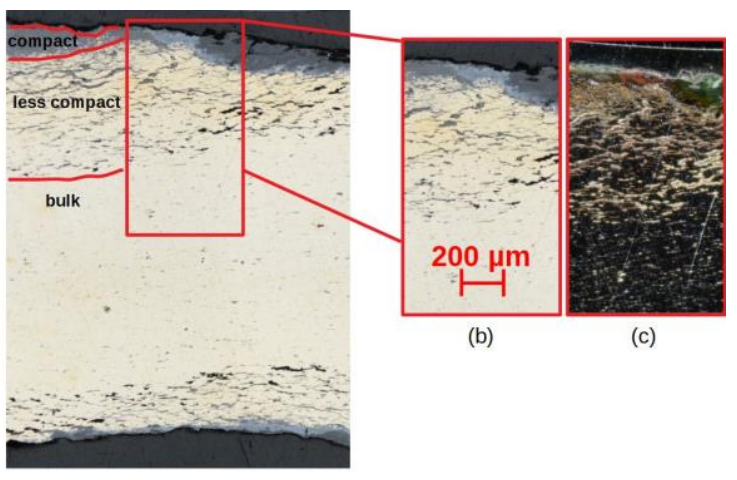

(a)

Figure 9. OM bright-field (a,b), OM dark-field (c ) images of the cross-section of the non-treated area of the bronze coin.
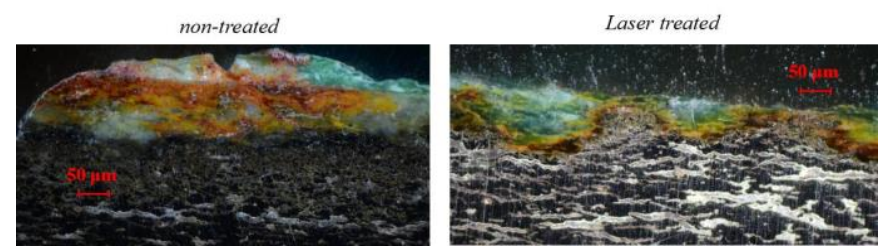

Figure 10. OM dark-field images of the cross-sections of non-treated (left) and laser treated (right) coin areas.

\section{CONCLUSIONS}

The preliminary results reported on $\mathrm{Cu}$ reference samples related with the laser cleaning of metallic artefacts pointed out interesting application perspectives, which motivate the need of future application tests on archaeological and historic metallic artefacts.

The behaviour of two different artificial corrosion layers, an oxide layer and a hydroxychloride layer, formed on $\mathrm{Cu}$-based reference samples was analysed before and after laser cleaning. A pulsed Near-IR laser was used in a Q-Switched regime and the laser parameters were fixed during the cleaning treatment of oxide and hydroxychloride artificial corrosion layers. Then, a validation of the laser cleaning procedure was performed on an ancient bronze coin.
After all the laser treatments performed on the reference samples, the optimal laser condition for both the artificial oxide and hydroxycloride corrosion layers were characterised by the lowest power and pulse duration (4 ns) and accepted as the ablation threshold for the unwanted layers.

Since the ancient corrosion products layer is thicker and more compact than the artificially tested ones, a reduction of the unwanted corrosion products was observed, even if not in a complete and homogenous way. Moreover, the artificial corrosion layers and the archaeological corrosion layers seemed not altered in their compositions.

In conclusion, the laser ablation can remove successfully and in a highly controlled way the corrosion layers without modifying the composition of the remaining corrosion products. However, a further validation on real artefacts is mandatory due to the variation in thickness and composition of the corrosion products formed during long-lasting uncontrolled degradation processes.

\section{ACKNOWLEDGEMENTS}

The Authors would like to thank the European Federation of Corrosion (EFC) for supporting the Raman measurement campaign in the frame of the EUROCORR Young Scientist Grant 2016. A special thanks to Jacopo Corsi for the bronze coin donation.

\section{REFERENCES}

[1] L. Lombardo, S. Corbellini, M. Parvis, A. Elsayed, E. Angelini, S. Grassini, Wireless Sensor Network for Distributed Environmental Monitoring, IEEE Transactions on Instrumentation and Measurement, Volume 67(5), 2018, pp. 1214 1222.

[2] S. Corbellini, E. Di Francia, S. Grassini, L. Iannucci L. Lombardo, M. Parvis, Cloud based sensor network for environmental monitoring, Measurement: Journal of the International Measurement Confederation, vol. 118, 2018, pp. 354-361.

[3] E. Angelini, F. Civita, S. Corbellini, D. Fulginiti, S. Grassini, M. Parvis, Innovative monitoring campaign of the environmental conditions of the Stibbert museum in Florence, Applied Physics A, Materials Science \& Processing, Volume 122-123, 2016, pp.112.

[4] C. Fotakis, Lasers for art's sake!, Optics \& Photonic News, 1995, pp. 30-35.

[5] F. Landucci, R. Pini, S. Siano, R. Salimbeni, E. Pecchioni, Laser cleaning of fossil vertebrates: a preliminary report, Journal of Cultural Heritage, Volume 1, 2000, pp. S263-S267.

[6] R. Pini, S. Siano, R. Salimbeni, M. Pasquinucci, M. Miccio, Tests of laser cleaning on archaeological metal artefacts, Journal of Cultural Heritage, Volume 1, Supplement 1, 2000, pp. S129-S137.

[7] C. Fenic, R. Dabu, A. Stratan, C. Blanaru, C. Ungureanu, C. Luculescu, Preliminary studies of material surface cleaning with a multi-pulse passively Q-switched Nd:YAG laser, Optics \& laser technology, Volume 36: 2, 2004, pp. 125-130.

[8] M. Matteini, C. Lalli, I. Tosini, A. Giusti, S. Siano, Laser and chemical cleaning tests for the conservation of the Porta del Paradiso by Lorenzo Ghiberti, Journal of Cultural Heritage, Volume 4:1, 2003, pp. 147-151.

[9] S. Siano, R. Salimbeni, R. Pini, A. Giusti, M. Matteini, Laser cleaning methodology for the preservation of the Porta del Paradiso by Lorenzo Ghiberti, Journal of Cultural Heritage, Volume 4:1, 2003, pp. 140-146.

[10] S. Siano, J. Agresti, I. Cacciari, D. Ciofini, M. Mascalchi, I. Osticioli, A. A. Mencaglia, Laser cleaning in conservation of stone, metal, and painted artifacts: state of the art and new insights on the use of the Nd:YAG lasers, Applied Physics A - Materials Science \& Processing, Volume 106, 2012, pp. 419-446. 
[11] C. Pelosi, L. Calienno, D. Fodaro, E. Borrelli, A. R. Rubino, L. Sforzini, A. Lo Monaco, An integrated approach to the conservation of a wooden sculpture representing Saint Joseph by the workshop of Ignaz Günther (1727-1775): Analysis, laser cleaning and 3D documentation, Journal of Cultural Heritage, Volume 17, 2016, pp.114-122.

[12] L. Robbiola, J.-M. Blengino, C. Fiaud, Morphology and mechanisms of formation of natural patinas on archaeological $\mathrm{Cu}-$ Sn alloys, Corrosion science, Volume 40:12, 1998, pp. 2083-2111.

[13] G. M. Ingo, T. de Caro, C. Riccucci, E. Angelini, S. Grassini, S. Balbi, P. Bernardini, D. Salvi, L. Bousselmi, A. Çilingiroglu, M. Gener, V. K. Gouda, O. Al Jarrah, S. Khosroff, Z. Mahdjoub, Z. Al Saad, W. El-Saddik, P. Vassiliou, Large scale investigation of chemical composition, structure and corrosion mechanism of bronze archeological artefacts from Mediterranean basin, Applied Physics A - Materials Science \& Processing, Volume 83, 2006, pp. 513-520.

[14] C. Soffritti, E. Fabbri, M. Merlin, G. L. Garagnani, C. Monticelli, On the degradation factors of an archaeological bronze bowl belonging to a private collection, Applied Surface Science, Volume 313, 2014, pp. 762-770.

[15] I. Constantinides, A. Adriaens, F. Adams, Surface characterization of artificial corrosion layers on copper alloy reference materials, Applied surface science, Volume 189: 1-2, 2002, pp. 90-101.

[16] T. Beldjoudi, F. Bardet, N. Lacoudre, S. Andrieu, A. Adriaens, I. Constantinides, P. Brunella, Surface Modification Processes on European Union bronze reference materials for analytical studies of Cultural Artefacts, Surface engineering, 17:3, 2001, pp. 231-235.
[17] K. P. Fitzgerald, J. Nairn, A. Atrens, The chemistry of copper patination, Corrosion science, Volume 40: 12, 1998, pp. 20292050.

[18] E. Di Francia, R. Lahoz, D. Neff, E. Angelini, S. Grassini, ToFSIMS and $\mu$-Raman measurements on laser cleaned bronze archaeological artefacts, Proceedings of $3^{\text {rd }}$ IMEKO International Conference on Metrology for Archaeology and Cultural Heritage, Lecce, Italy, 2017, pp. 295-298.

[19] K. Leyssens, A. Adriaens, E. Pantos, C. Degrigny, Study of corrosion potential measurements as a means to monitor the storage and stabilisation processes of archaeological copper artefacts, Proceedings of Metal 2004, National Museum of Australia Canberra ACT, 2004, pp. 332-342.

[20] M. Hrnjic, L. Alberto Angurel, R. Lahoz, S. Grassini, E. Angelini, N. Schiavon, G. F. de la Fuente, Near-IR laser cleaning of $\mathrm{Cu}-$ based artefacts: a comprehensive study of the methodology standardization, Proceeding of $1^{\text {st }}$ International Conference on Metrology for Archaeology Benevento, Italy, 2015, pp. 389-394.

[21] G. Bertolotti, D. Bersani, P. P. Lottici, M. Alesiani, T. Malcherek, J. Schlüter, Micro-Raman study of copper hydroxychlorides and other corrosion products of bronze samples mimicking archaeological coins, Analytical and Bioanalytical Chemistry, Volume 401, 2012, pp. 1451-1457.

[22] C. Fotakis, D. Anglos, V. Zafiropulos, S. Georgiou, V. Tornari, Lasers in the Preservation of Cultural Heritage: Principles and Applications, Taylor \& Francis Ltd., 2006, ISBN 9780750308731.

[23] C. L. Soto Quintana, Development and optimisation of protocols for surface cleaning of Cultural Heritage metals, Erasmus Mundus Master Thesis in Archaeological Materials Science, 2016. 